\title{
REFORMA ADMINISTRATIVA BRASILEIRA E A TERCEIRIZAÇÃO NO SETOR PÚBLICO
}

\author{
Julio Cesar da Silva
}

I-Introduçāo; 2 - Desenvolvimento; 2.1 - Caracteristicas dos serviços públicos a partir da reforma administrativa; 2.2 - O princípio da eficiência da administração pública como base para a opção administrativa de "terceirização dos serviços"; 2.3 - Reforma Administrativa e Terceirização; 2.4 - A Terceirização no Serviço Público: estabelecendo conceitos; 2.4.1 - Visão histórica; 2.4 .2 - As implicações da "terceirização": no direito trabalhista; 2.4 .3 - As posições dos tribunais de controle; 2.4 .4 - Algumas peculiaridades dos contratos de terceirização de serviços; 2.4 .5 - A contratação sem licitação e a terceirização; 2.4 .6 - A onda privatizante e os reflexos na terceirização; 2.4 .7 - A reestruturação de serviços públicos e privados; 2.4 .8 - Questões controvertidas sobre "terceirizaçāo"; 3 - Conclusão; 4-Bibliografia

\section{1 - Introdução}

A TERCEIRIZAÇĀO DOS SERVIÇOS PÚBLICOS deve ser examinada num amplo contexto em que diversas ações políticas passaram a representar uma contenção da expansão da máquina pública administrativa, que ganhara um espaço significativo, mas demonstrava, por seu gigantismo e ineficiência, que estava saturada e carente de sofrer um processo de reforma de suas bases conceituais.

Dentro do processo de DESESTATIZAÇÃO que teve como fatores determinantes os problemas orçamentais, as insatisfações decorrentes das ineficiências das empresas estatais, a necessidade de serem criados novos estímulos para incrementar $o$ investimento produtivo, a indicação de perspectivas de ganhos fiscais e a necessidade de liberação de maiores recursos humanos e financeiros, o ESTADO BRASILEIRO passou a buscar desde o PND/79 - PROGRAMA NACIONAL DE DESBUROCRATIZAÇÃO - e do PROGRAMA FEDERAL DE DESESTATIZA-

R. Dir. Adm.,

Rio de Janeiro, 217: 13-30, jul./set. 1999 
ÇÃO de 90 a 92 novos caminhos para um processo gradativo de DESREGULAMENTAÇÃO.

Este processo de DESESTATIZAÇÃO passou a ser cumprido através de projetos, desenvolvidos, prioritariamente, nas décadas de 80 e 90 , que podem ser grupados em, pelo menos, quatro grandes conjuntos: PRIVATIZAÇÃO, CONCESSÃO DE SERVIÇOS PÚBLICOS, PUBLICIZAÇÃO e DESREGULAMENTAÇÃO.

$\mathrm{Na}$ verdade, apesar de a intensificação dos procedimentos de REFORMA AD. MINISTRATIVA serem mais recentes, há duas experiências antecessoras que podem ser citadas na raiz desse tema: a reforma do periodo Vargas, que atendeu ao objetivo de fortalecimento do Estado Nacional, ampliando suas funções, adotando os princípios da administração burocrática clássica e a reforma do Decreto-lei $n^{0} 200 / 67$. que estimulou o fortalecimento da administração indireta e antecipou muitos dos princípios da administração gerencial no Brasil.

A década de 80 , foi marcada pela intensificação da crise do Estado no Brasil, o que pode ser constatado em diversos outros países, refletindo um processo de transformação com características globais.

Múltiplas e diversificadas são as variantes desse processo de Reforma Administrativa, mas alguns dos objetivos são gerais e podem ser resumidos a uma grande proposta: aumentar a capacidade administrativa do Estado, limitando as suas ações àquelas que lhe são próprias e descobrindo formas alternativas de gestão.

A redução dos custos e o aperfeiçoamento da máquina administrativa exigiu a descentralização dos serviços. A redução dessa atividade do Estado, além da privatização encontra diversos caminhos: desde a "declaração do serviço público", pela via da concessão e da permissão.

A permissão pode referir-se a uma atividade meio da administração, voltando-se o contrato quer para outra pessoa jurídica integrante da administração, quer para outra pessoa jurídica não integrante da administração, ou para pessoa física com as mesmas possibilidade das pessoas jurídicas, podendo os serviços serem prestados no estabelecimento do contratado ou da administração. Neste contexto, passou a ser ampliada a possibilidade de terceirização, interessando-nos o estudo mais de perto das alternativas para atendimento às atividades meio da administração.

Objetiva esse ensaio o estudo do instituto da TERCEIRIZAÇÃO DOS SERVIÇOS A PARTIR DA REFORMA ADMINISTRATIVA, colocando em destaque os pontos controvertidos desse processo na realidade da administração brasileira, com ênfase no contexto da administração municipal.

Há 20 anos, em pleno regime militar, começavam a ser detectados no Brasil os primeiros sintomas de saturação da atividade empresarial do Estado. Mesmo limitadas pelo autoritarismo, as manifestações de lideranças empresariais e de observadores econômicos acerca do que percebia como estatização excessiva acabaram produzindo reações por parte do governo. A mais nítida foi, provavelmente, a criação da Secretaria de Controle das Empresas Estatais, em 1979.

Durante a década de 80 , apesar de novas empresas estatais terem sidos constituídas, ocorreram algumas transferências de propriedade do setor público para o 
privado. Essas transferências, contudo, apenas desenvolveram ao controle privado empresas anteriormente encampadas pelo poder público.

Nem por isso o trabalho realizado na época deve ser subestimado. Foram efetuados demorados levantamentos que afinal permitiram um mapeamento criteriosos dos itens que compunham o patrimônio do setor público. Só então foi possível imprimir velocidade e dilatar o alcance do processo de desestatização, como fez o governo Collor, já nos anos 90 , num contexto mais amplo de reformas modernizantes.

Cabe salientar que esta análise enfatiza o papel das terceirizações nesse processo de mutações de funções entre os setores públicos e privados.

Os procedimentos de terceirização desafiam a administração pública nos tempos em que as funções do Estado sofrem uma revisão a partir da Reforma Administrativa e merecem estudos que possibilitem a sua melhor compreensão.

\section{2 - Desenvolvimento}

O problema a ser enfrentado pela administração pública, na busca de uma eficiência, apesar de necessária redução de recursos, parece instaurar um obstáculo intransponível: manter o desenvolvimento, $o$ atendimento aos anseios sociais, mesmo diante de crise econômica de proporções gigantescas.

$\mathrm{O}$ crescimento acentuado do Estado, fenômeno mundial que caracterizou o século passado e o início deste, estendeu com bastante amplitude a dimensão do conceito do serviço público, gerando um intervencionismo que procurava suprir a ausência de participação da iniciativa privada e, por outro lado, implementá-la de forma a possibilitar a ampliação dos serviços.

Surge, então, uma série de questões polêmicas, dentre as quais a que confronta a ineficiência do Estado burocrata com a presença maior da iniciativa "particular eficiente", fazendo germinar a busca de alternativas legais para enfrentar problemas da Administração Pública.

No Brasil de FHC, a questão do agigantamento do Estado encontra resistência e reação, notadamente quando o País elegeu um Presidente da República com modelo neoliberal, que consiste precisamente na idéia de restringir a atividade do Estado, ao extremamente mínimo necessário, deixando o exercício da atividade econômica para iniciativa privada.

Se a redução do paternalismo estatal representa o fortalecimento dos que detém o capital, mesmo que custe sacrifícios "sociais", estamos diante de uma opção política com diversificadas conseqüências na vida econômica brasileira, sendo, portanto, o reflexo de um ideário.

Inicialmente, examinaremos as características dos serviços públicos a partir da reforma administrativa, para atingirmos o núcleo central de nosso estudo, assinalando o papel da terceirização no serviço público e concluindo com a análise dessa opção administrativa no contexto da administração municipal. 


\section{1 - Serviços Públicos: suas características a partir da Reforma Administrativa}

Para o desempenho de suas atividades o Estado depende de recursos e da utilização de seu pessoal. A constante alternância de períodos de crise econômica representou nas últimas décadas um crescente desafio: como cumprir sua função básica de realização do bem público material e moral da coletividade?

Hely Lopes Meirelles conceitua de maneira cristalina:

"serviço público é todo aquele prestado pela administração ou por seus delegados, sob normas e controles estatais, para satisfazer necessidades essenciais ou secundárias da coletividade ou simples conveniências do Estado"

Há serviços públicos que são privativos do Estado, sendo impossível incluir-se em contexto de terceirização. São classificados como "serviços públicos propriamente ditos". Outros, são os chamados "serviços próprios do Estado", que também estão relacionados com as atribuições do Poder Público. os quais também não admitiriam a terceirização. Há serviços classificados como "uti universi gerais" prestados sem usuários determinados, sendo indivisíveis e, logicamente, inatingíveis pelo processo de terceirização. Há os "serviços administrativos", os quais não se referem ao direto atendimento à população, atendendo às necessidades internas da administração. não cabendo o exame da possibilidade de terceirização. Os serviços que podem ser delegados ou praticados por entidades descentralizadas são os chamados "serviços impróprios do Estado".

A Constituição Federal do Brasil estabelece, em seu art. 175, que ao Poder Público compete a prestação de serviços públicos.

$\mathrm{Na}$ busca de uma eficiência administrativa pode o Estado terceirizar algumas de suas atividades, dentro de processos de delegação.

A Reforma Administrativa propõe um repensar dos conceitos de prestação dos serviços públicos, sobretudo incluindo o princípio da "eficiência" como justificador dos procedimentos básicos, tanto da administração direta como da administração indireta.

Um dos caminhos para envolver a iniciativa privada na realização dos serviços públicos é através das "Organizações Sociais". A possibilidade de contratação através de "seleção", desobrigadas de "concurso público" e utilizando o intituto da "contratação temporária", mediante Contrato de Gestão.

A figura jurídica da "terceirização de serviços públicos" não decorreu diretamente da reforma administrativa realizada na década de 90 , mas ampliou seu sentido a partir de uma política de desregulamentação.

\section{2 - O princípio da eficiência da administração pública como base para a} opção administrativa de "terceirização de serviços"

A emenda constitucional $n^{0}$ 19/98 alterou o art. 37 da CF. incluindo o princípio da "eficiência" aos princípios constitucionais da administração pública, que já era 
considerado, por alguns autores. como implicitamente presente na Carta Magna de $1988 \mathrm{em}$ seu art. 74, II.

Evidentemente que a administração deve traçar seus objetivos e buscar caminhos para atingir os resultados de interesse público. Cada vez mais, a conquista dos resultados desejados pela população representa o maior desafio para os administradores.

Há uma interligação do princípio da eficiência com os princípios da razoabilidade e da moralidade, pois o administrador, ao realizar sua atividade discricionária deve procurar o melhor critério.

Podemos, então, entender a EC $n^{2} 19 / 98$ como uma permissão à União, aos Estados, ao Distrito Federal e aos Municípios para que realizem uma gestão dos serviços públicos associada, transferindo alguns dos encargos para atividades terceirizadas.

Alexandre de Moraes, in "Reforma Administrativa" examina com propriedade as características desse princípio da eficiência:

"o princípio da eficiência compõe-se, portanto, das seguintes características básicas: direcionamento da atividade e dos serviços públicos à efetividade do bem comum, imparcialidade, neutralidade, transparência, participação e aproximação dos serviços à população, eficácia, desburocratização e busca de qualidade"

Impondo-se ao administrador, através de avaliação periódica de desempenho, um acentuado compromisso com a eficiência, coloca-se, então, a opção pela terceirização como uma das alternativas a ser examinada pelo administrador, em sua busca permanente de aperfeiçoamento de seus serviços.

A questão que se coloca para o Administrador é a de buscar atingir com os limitados recursos disponíveis, - que ficam a cada dia mais reduzidos pela crise financeira enfrentada - os objetivos básicos para o desenvolvimento da economia e para o atendimento nas áreas essenciais.

Comprometido com a eficiência administrativa, no momento em que tramita no Congresso Nacional lei que estabelecerá severa punição para os que não realizarem um trabalho administrativo eficiente, a decisão pela terceirização de alguns serviços pode ser uma alternativa correta.

\section{3 - Reforma Administrativa e Terceirização}

A política de Reforma Gerencial que dá ênfase à terceirização das atividades de apoio foi iniciada pelo Decreto-Lei ${ }^{2} 200 / 67$, o qual ainda está em plena vigência. Mais recentemente, o Decreto $n^{2} 2.271$, de 7 de julho de 1997, também tratou da matéria e no conjunto das mudanças determinadas pelo processo de Reforma Administrativa podemos dizer que as indicações principais para que a Administração faça a opção por terceirizar serviços limitam-se às áreas que não sejam próprias ou exclusivas do Estado. 
De tal maneira. as atividades de apoio poderiam ser terceirizadas. possibilitando que sejam realizadas pela iniciativa privada. O ponto de partida para a definição do quadro de atividades que poderiam ser terceirizadas fica então sendo a própria distinção de atividades que são próprias e exclusivas do Estado e as que são semeIhantes ou idênticas às atividades realizadas por empresas privadas.

A terceirização de atividades de natureza acessória poderia ser exemplificada em atividades de conservação, limpeza. segurança, vigilância. transportes, informática, copeiragem, recepção, reprodução de documentos, telecomunicações, manutenção de prédios, equipamentos e instalações.

As condições básicas para uma opção por terceirizar serviços devem ser: a garantia de maior eficiência na realização dos serviços e a garantia de maior economia de custos.

$O$ instituto da administração indireta pela via da terceirização permitiu a ampliação das atividades que podem ser realizadas e aperfeiçoou as regras limitadoras que condicionam os valores dos contratos aos preços do mercado, estabelecendo normas de fiscalização e avaliação da eficiência dos serviços, objetivando: assegurar a economicidade dos contratos, evitar o desvirtuamento da terceirização e possibilitar uma constante avaliação da execução dos contratos.

Dentre as regras impeditivas podem ser destacadas:

a) Não pode haver vínculo de subordinação entre os empregados da Contratada e dirigentes do órgão contratante;

b) Não podem existir cláusulas de reajuste automático de valores do contrato;

c) Nas alterações dos preços de mercado em contratos de execução contínua de serviços deve haver um aditamento com estabelecimento de novas condições;

d) Os editais de licitação devem fixar os valores máximos de preços, evitando a manipulação pelos licitantes que poderia ocasionar um preço final.

A reforma constitucional que passou a ser chamada de "reforma administrativa", dentre diversos temas, redefiniu as estratégias de gerenciamento administrativo. ampliando as possibilidades de terceirização.

A polêmica instaurada a partir dessas regras pode ser colocada quanto aos limites da terceirização, quanto aos seus fundamentos e ao conflito com as características essenciais de uma administração pública.

\section{4 - A terceirização no serviço público: estabelecendo conceitos}

\subsection{1 - Visão histórica}

A terceirização não é o único instrumento no âmbito da legislação vigente que possibilite a redução da participação do Estado em tarefas impróprias, mas é um dos mais controvertidos e merece estudo destacado. Os limites desse instrumento permitem vislumbrar a fronteira final do serviço público, em precisa consonância com a atual política de reforma Gerencial do Estado que vem sendo implementada pelo 
atual governo e cujas raízes no direito positivo brasileiro podem ser identificadas há cerca de três décadas.

A Administração Pública Brasileira tem demonstrado, na aplicação do instituto muitas contradições. o que demonstra incompreensão e inobservância de critérios básicos, ora tratando de forma extensiva. ora deixando de usar as possibilidades do instituto.

Segundo o autorizado magistério do professor Sérgio Pinto Martins, a terceirização consiste na possibilidade de contratar terceiro para a realização de atividades que não consistem o objeto principal da impresa. Essa contratação, esclarece o mesmo jurista, pode envolver tanto a produção de bens, como de serviços, como ocorre na necessidade de contratação de serviços de limpeza, de vigilância e até de serviços temporários.

Durante expressivo período da história ocidental o Estado foi com frequiência o paradigma da iniciativa privada, como exemplifica o próprio desenvolvimento do Direito do Trabalho, a partir do final do século XIX, na França, abolindo-se o marchandage, o qual consistia precisamente na intermediação de mão-de-obra, sob o argumento de que não sendo o trabalho mercadoria descaberia a sua intermediação.

No Brasil, após o fortalecimento da CLT, na era Vargas, o processo de intermediação de mão-de-obra ficou proibido e somente passou a ser admitido a partir da metade da década de 60 , quando se inicia, timidamente, a partir da necessidade de contratação de serviços de segurança para os bancos que sofriam com os saques de grupos armados com objetivos políticos, além dos costumeiros assaltos por quadrilhas. $O$ amparo legal para essas contratações foi dado pelos decretos-lei $\mathbf{n}^{\circ}$ 1.212 e 1.216 .

\subsection{2 - As implicações da "terceirização" do direito trabalhista}

Jorge Ulisses Jacoby Fernandes, in "A terceirização no serviço público", trabalho divulgado pelo CEBRAD, assinala os moldes históricos dessa evolução, sobretudo ressaltando as raízes do instituto no direito do trabalho.

Após a década de 60, copiando uma recém editada lei francesa, o Brasil permite a contratação do trabalho temporário, nos moldes da lei 6.019 , de 3 de janeiro de 1974, e nessa linha evolutiva, a Lei 7.102, a qual revogando o Decreto-Lei 1.034/69 melhor disciplinou a contratação de empresas de segurança.

"A Justiça do Trabalho repeliu diversas tentativas da terceirização. O TST declarava que a mão-de-obra no Brasil era muito barata. Permitir a terceirização significaria acolher um intermediário na relação de emprego, que unicamente se remuneraria de parcela do salário já aviltado"

A Justiça do Trabalho, buscando assegurar a plenitude dos direitos trabalhistas repeliu diversas iniciativas de terceirização, evitando o que entendia ser o verdadeiro aviltamento da mão-de-obra. No entendimento de nossos tribunais, permitir-se a terceirização da mão-de-obra num país que já se caracteriza pelo baixíssimo salário 
mínimo seria permitir a instauração de uma condição maior de aviltamento e a supressão das garantias trabalhistas.

Sendo o conceito de "empregado" construído no Direito do Trabalho, tanto pela doutrina como pela jurisprudência é reconhecida a relação de emprego quando a partir de atributos como pessoalidade (os serviços devem ser prestados pessoalmente): onerosidade (os serviços devem ser remunerados); continuidade (os serviços devem ser prestados de forma não-eventual); subordinação (na prestação dos serviços. o agente deve acatar ordens) e. finalmente a intencionalidade na relação de emprego

Nesse diapasão, a terceirização que se opera com prestação de trabalho no estabelecimento do prestador de serviços foi ampliando seus horizontes, como ocorreu, sobretudo com a expansão da indústria automobilística.

Em linha diretamente oposta, a terceirização que se opera com a subordinação direta da pessoa física, prestadora do serviço ao contratante do serviço foi repelida. Nessa dimensão, a terceirização que se efetiva no estabelecimento da empresa que pretende ver sua atividade terceirizada, ou que gerencia diretamente o grupo de trabalho, foi atrofiada.

Mudava-se a posição dos Tribunais e o Tribunal Superior do Trabalho passava a admitir a terceirização do serviços de vigilância e conservação conforme retrata o cnunciado no 256 da jurisprudência uniforme desse Tribunal que estabelecia:

“256. Salvo os casos de trabalho temporário e de seniços de vigilância, previstos nas Leis n. 6.019, de 3 de janeiro de 1974, e 7.102 de 20 de junho de 1983, é ilegal a contratação de trabalhadores por empresa interposta, formando o vínculo empregaticio diretamente com o tomador de serviços."

Tomando como ponto de partida para exame do tema da terceirização no serviço público o texto do Decreto-Lei 200/67, que recomendava a terceirização, enunciando, no seu art. $10, \S 7^{\circ}$ nos seguintes termos:

\section{"Capitulo III - da descentralizaf̧ão}

art. 10 a execução das atividades da Administração Federal deverá ser amplamente descentralizada.

$\S 7^{\boldsymbol{a}}$ Para melhor desincumbir-se das tarefas de planejamento, coordenação, supervisão e controle e com o objetivo de impedir o crescimento desmesurado da máquina administrativa, a Administração procurará desobrigar-se da realização material das tarefas executivas, recorrendo, sempre que possível, a execução indireta, mediante o contrato, desde que exista, na área, iniciativa privada suficiente desenvolvida e capacitada a desempenhar os encargos de execução.

Passou a existir um conflito jurídico no entendimento das contratações, pois se a Administração também contratava mediante a CLT e a Justiça do Trabalho julgava, tendo em conta os princípios gerais desse ramo do Direito, entre os quais a observância dos requisitos da relação do trabalho, as questões que passaram a ser levadas 
para os tribunais eram relativas aos que tendo sido contratados para serviços de terceirização passavam a pleitear os direitos de relação de emprego.

A Justiça Federal trilhou o mesmo entendimento, consagrando a súmula no 214 do Tribunal Federal de Recursos que dispõe:

"A prestação de serviços em curácter continuado, em atividades de natureza permanente, com subordinação, observância de horário e normas da repartição, mesmo em grupo-tarefa, configura relação empregatícia."

A origem do problema estava pois na possibilidade de a administração contratar mediante o regime da Consolidação das Leis do Trabalho, misturado-se com as figuras desenvolvidas pelos contratados por terceirizadas.

A questão foi reaberta pela tese consagrada na Reforma Administrativa do Estado pela qual o regime de CLT, passa a ser consagrado como próprio para reger as relaçōes de trabalho dos servidores públicos, o que é extremamente controvertido e, a nosso ver, equívoco no tratamento da questão.

Considerando que a atuação do Estado na atividade econômica, pelas regras da Carta Magna, constitui, hoje, uma exceção, e só no âmbito dessa exceção é que se admite a aplicação do regime contratual, batizado pela CLT, a aplicação das normas da CLT para reger a relação do servidor público é. ao mínimo, controvertida.

A Constituição Federal de 1988, acolhendo a classificação dos agentes públicos de Oswaldo Aranha e Bandeira de Mello estabeleceu a categoria dos servidores públicos, subdividindo-a, entre servidores públicos civis - ligados à administração Direta, Autárquica e Fundacional - e os servidores públicos empregados - ligados à administração Indireta.

Surge a noção de Regime Jurídico Único - RJU - para servidores públicos civis e a possibilidade da aplicação da CLT para servidores públicos empregados. conforme dispôs o art. $173 \S 1^{\circ}$ do estatuto político fundamental, que, à propósito, lembre-se permite a exploração da atividade econômica pelo Estado nas duas restritíssimas hipóteses que elenca no caput.

Para ambos os regimes de trabalho - RJU e CLT - foi estabelecido no art. 37, inciso II, a obrigatoriedade da prévia participação e aprovação em concurso público.

Com essa exigência, de índole constitucional, a caracterização da relação de emprego com a Administração passou a requerer o concurso público.

Não se pode dizer, na realidade jurídica de hoje, que exista qualquer possibilidade de uma pessoa que presta serviço para o Estado, através de empresa contratada possa requerer - como no passado - a sua vinculação trabalhista com a Administração Pública, conforme cristalina posição jurisprudencial, estampada no enunciado 256, revisto pelo enunciado 331 , passando a ter a seguinte redação:

I - a contratação de trabalhadores por empresa interposta é ilegal, formando-se o vínculo diretamente com o tomador dos serviços, salvo no caso de trabalho temporário (lei $n^{\prime 2} 6.019$, de 3 de janeiro de 1974). 
Il - a contrataçăo irregular de trabalhador, através de empresa imterposta. não gera vínculo de emprego com os órgãos da Administração Pública Direta. Indireta ou Fundacional (art. 37, inc. II, da Constituição da República).

III - não forma vínculo de emprego com o tomador a contratação de serviços de vigilâncias (Lei n 7.102, de 20 junho de 1983), de conservação e linpeza, bem como a de serviços especializados ligados - atividades-meio do tomador. desde que inexistente a pessoalidade e a subordinação direta.

IV - o inadimplemento das obrigações trabalhista, por parte do empregador, implica na responsabilidade subsidiária do tomador de serviços quanto aquelas obrigações, desde que este tenha participado da relação processual e conste também do título executivo judicial.

A mudança na jurisprudência representou um estímulo à terceirização, visto que não mais existe o perigo do reconhecimento judicial da relação de emprego com o Estado, pela falta do preenchimento do requisito imprescindível que o reclamante tenha se submetido previamente ao concurso público.

\subsection{3 - A posição dos Tribınais de Controle}

A Administração Pública se submete ao controle externo por parte dos Tribunais de Contas, o que torna necessário o exame da possibilidades de terceirização sob a perspectiva dos Tribunais de Controle.

Em reiteradas decisões o Tribunal de Contas da União vem julgando irregular a contratação de empresas para a prestação de serviços quando as tarefas a serem desenvolvidas integram o elenco das atribuições dos cargos permanentes.

Nesse sentido, cumpre destacar o julgamento dos processos TC-225.096/93-5, TC-475.054/95-4, TC-000.384/90-9, entre outros inúmeros, entendendo aquela Corte que em razão dos Decretos $71.236 / 72,74.448 / 74$ e Leis 5.645/70 e 5.845/72, não é possível terceirizar atividades típicas de cargos permanentes.

Existe uma possibilidade de consideração especial dessa matéria em situações de contratação para tarefa prevista para cargo colocado em extinção ou quando ocorrer aumento substancial da demanda, em carácter temporário.

\subsection{4 - Algumas peculiaridades dos contratos de terceirização de serviços}

Dentre inúmeros aspectos que podem ser tratados sobre o tema da terceirização assume relevância da participação do órgão de recursos humanos, na gestão de recursos, sem subordinação direta ao tomador de serviços. 
Leciona Jorge Ulisses Jacoby Fernandes:

Ao contrário do que ocorria no passado, em que o órgão de pessoal se traduzia como mantedor da folha de pagamento, hoje o agente de recursos humanos é verdadeiro gerenciador de conflitos interpessoais, e não há desafio maior do que buscar o estreitamento dos vínculos entre o órgão e o pessoal da empresa da atividade terceirizada.

Estabelece a Lei n" 8.666/93, que trata das licitações e contratos a obrigatoriedade do projeto básico, para a contratação de qualquer obra ou serviço.

Efetivamente o art. $7^{*}$, notadamente no $\$ 2^{2}$, inciso I, da Lei epigrafe, coloca a necessidade da prévia elaboração do projeto básico, estabelecendo que somente poderão ser licitados os serviços e as obras, depois de atendida essa exigência.

Projeto básico. para obras e serviços é definido pelo autor como o que corresponde ao detalhamento do objeto de modo a permitir a perfeita identificação do que é pretendido pelo órgão licitante e, com precisão, as circunstâncias e modo de realização.

Quando o objeto inclui a prestação do serviço no estabelecimento do contratante, o objeto prático é um instrumento essencial para a integração entre as áreas. Nesse sentido, por exemplo, o conhecido contrato para conservação e limpeza de uma unidade integrará as diversas áreas como o recursos humanos, a segurança e todos os locais a serem conservados.

O que se deve definir, então, é o projeto a ser desenvolvido e os critérios para avaliação das atividades realizadas através de serviços terceirizados para que se garanta o controle da eficiência, razão maior para a opção da Administração Pública pelos serviços terceirizados.

Como se vê, em breves linhas, a precisa definição do objeto, que se coloca no projeto básico, aliado a um treinamento introdutório, recomendável quando há contato entre os servidores e o pessoal do contratado, pode funcionar para o aperfeiçoamento da Administração Pública.

Para o acompanhamento dos serviços terceirizados, destaca-se a figura do executor do contrato, que é o agente da Administração responsável pela fiscalização e fiel acompanhamento do ajuste, constituindo-se em verdadeiro representante da administração.

Os Tribunais de Contas costumam questionar e responsabilizar os executores dos contratos imperfeitos, de obras inexistentes, de desperdícios e erros na execução. A prática da Administração tem sido simplista e equivocada, cabendo, muitas vezes, a um funcionário atestar serviços, para cumprir a formalidade, sem que tenha efetivamente acompanhado qualquer coisa, o que traduz uma irregularidade grave que pode levá-lo a uma situação de justificar perante os Tribunais de Contas a fidelidade do que atestou nas faturas. 


\subsection{5 - A contrataşão sem licitação e a terceirizạ̧ăo}

Há casos em que a terceirização pode ocorrer sem licitação, conforme é previsto na própria legislação, cabendo destacar na Lei $n^{0} 8.666 / 93$ o art. 24 tem dispositivos específicos:

I-Art. 24, Inc. VIII, que estabelece os seguintes requisitos para que se opere legitimamente a contratação direta:

a) que o contratante seja pessoa jurídica de direito público interno;

b) que o contratado seja órgão ou entidade que integre a Administração Pública;

c) que o contratado tenha sido criado para o fim específico do objeto pretendido pela Administração contratante;

d) que a criação ou entidade contratado tenha ocorrido antes da vigência da Lei 8.666/93;

e) que o preço seja compatível com o praticado no mercado.

II - Art. 24, Inc. VIII, que estabelece os seguintes requisitos para que se opere legitimamente a contratação direta:

a) que o contratado seja instituição brasileira:

b) que no estatuto ou no regimento do contratado seja expressamente declarado que o objetivo da instituição constitua-se;

b.l) na dedicação à pesquisa, ensino, ou desenvolvimento institucional;

b.2) alternativamente ao requisito da alínea anterior, o objetivo declarado no estatuto ou regimento seja a recuperação social do preso;

c) que o futuro contratado detenha inquestionável reputação ético-profissional,

d) que o futuro contratado não tenha fins lucrativo;

III - Art. 24, Inc. $X X$, que estabelece os seguintes requisitos para que se opere legitimamente a contratação direta:

a) o primeiro, atinente as qualificaçōes do contratado que deverá ser:

- associação de portadores de deficiência física:

- sem fins lucrativos; $\mathrm{e}$

- de comprovada idoneidade.

b) o segundo, referente ao objeto pretendido, qual seja:

- prestação de serviços;

- fornecimento de mão-de-obra.

c) o terceiro, referente ao preço do contrato que deve ser compatível com o praticado no mercado.

Há, portanto, hipóteses em que a contratação pode ocorrer sem a licitação, o que demonstra a posição do legislador em oferecer alternativas para a Administração Pública buscar novos caminhos para o melhor desempenho de suas funções.

\subsection{6 - A onda privatizante e os reflexos na terceirização}

Globalização, parceria e participação surgem como as tendências dominantes de nossa época. que, por sua vez, repercutem intensamente na área da prestação dos serviços públicos. 
$\mathrm{Na}$ época atual, as questões que se colocam são: como melhor prestar os serviços que são esperados da administração pública? Como se presta esse serviço? Por que se tem de prestar? Quem tem de prestar? Sob qual regime deve ser prestado o serviço? Cresce cada vez mais a consciência política do cidadão, amadurece a compreensão dos seus direitos e a exigência de que os governantes cumpram suas funções.

$\mathrm{Na}$ medida em que a intervenção estatal na economia cede cada vez mais passos à forma da parceria com a iniciativa privada; em que se busca a retirada da presença do Estado em certos setores da atividade econômica para assegurar-lhe maior eficiência em suas áreas mais próprias e específicas de atuação, cresce em todos os setores da atividade pública, uma verdadeira onda privatizante.

Em um primeiro momento, procura o Estado retirar-se das atividades econômicas, desestatizando suas empresas estatais exploradoras de atividades econômica em regime de competição de mercado.

Orienta-se, em uma Segunda etapa, para privatização das empresas estatais criadas exclusivamente para a prestação de serviços públicos, às quais se atribuiu, para fins operacionais, na tentativa, nem sempre bem sucedida, de alcançar maior flexibilidade de ação, um regime híbrido, predominantemente sujeito ao direito privado.

Por último, direciona-se o Estado para a impropriamente chamada "privatização" de serviços públicos.

Evidentemente, não se trata da privatização, pois é da essência conceitual desta a retirada total da presença do Estado de uma empresa ou atividade.

$\mathrm{Na}$ sequiência dessa onda privatizante, a possibilidade de terceirização dos serviços assume uma posição destacada como uma das formas de delegação delegação de prestação de serviços públicos e particulares, sob a inafastável e indeclinável regulação, fiscalização e controle do Poder Público. que conserva, sempre, para todos os efeitos, por ser da essência mesma de toda delegação, sua plena titularidade.

Em tais condições, ganha extremo relevo, antes as tendências fundamentais da época em que vivemos. o estudo das diversas formas de delegação da prestação de serviços públicos, notadamente na forma que examinamos nesse ensaio através da terceirização dos serviços públicos.

A promulgação, em um só ano, das duas Leis Federais, números 8.987/95 e 9.074/95, é fato extremamente sintomático, harmonizando-se perfeitamente, pois, com a crescente tendência, no panorama mundial e no cenário jurídico nacional, para o ressurgimento das formas delegadas de prestação de serviços públicos, tão em voga no século passado e o início deste podemos dizer que a terceirização é uma forma naturalmente decorrente dessa onda de interpenetrar atividades públicas e privadas.

\subsection{7 - A reestruturação de serviços públicos e privados}

Tantos nos países de Primeiro Mundo como nos países em desenvolvimento a natureza específica social dos serviços privados e a natureza dos serviços públicos 
sofreram gradativas transformaçōes. igualando diferenças e estabelecendo maiores alianças na busca de aperfeiçoamento na prestação de serviços públicos.

Essas mudanças foram conquistadas pela busca na eficiência nos serviços de saúde. na coleta de lixo, nos trabalhos de manutenção e limpeza de repartições. nos serviços de informatização e $\mathrm{em}$ muitos outros considerados fundamentais para que a Administração alcance melhores resultados e mantenham custos reduzidos.

A característica de subcontratação de partes dos serviços de empresas especializadas. especialmente de produtos auxiliares às empresas. repercutiu no setor privado pelo crescimento de serviços privados de produtores de atividades gerenciais, enquanto, no setor público, são representados pela privatização e contratação ou terceirização de serviços.

Apesar de os serviços privados terem recebido maior atenção em estudos recentes, os serviços públicos agregam uma grande parte do emprego em serviços. Esses serviços são fornecidos através de várias combinações e algumas dessas combinações operam conjuntamente estabelecendo uma verdadeira interpenetração de funções.

Embora em grande parte dos países o setor público vem gradualmente se retirando de funções e atividades consideradas não essencialmente sociais, os serviços públicos ainda representam uma contribuição significativas para as economias.

Resumindo as idéias encontradas na bibliografia sobre as causas da reestruturação do setor público em muitos países de vários níveis de devenvolvimento, desde os anos 60, é possível identificar os seguintes fatores "a) demanda para a melhoria dos serviços de Saúde e Educação; b) expansão da infra-estrutura de Transporte e de Comunicações; c) crescimento dos gastos com defesa em certos países selecionados, refletindo até o final dos anos 80 a "Guerra Fria" entre o Leste e o Oeste; d) mudanças demográficas, que incluíam o crescimento da proporção de idosos sobre a população, com maior necessidade de serviços de Saúde e Previdência; e) mudanças na composição familiar, que incluíam um aumento no número de mulheres que trabalham fora da residência e o crescimento no número de famílias com apenas um dos pais, o que aumenta a demanda para o cuidado de crianças e serviços relacionados; f) políticas intervencionistas durante as décadas de 60 e 70 , no sentido de dirigir o crescimento econômico e a restruturação, requerendo maior número de trabalhadores governamentais; g) maior controle físico do planejamento para restringir ou conduzir o crescimento urbano e industrial e, assim minimizar os impactos ambientais; $h$ ) as melhorias em todas as partes do setor público eram vistas como sendo parte integral do longo "boom" econômico pós - 1945 até meados da década de 70 ; i) mais recentemente, o crescimento do desemprego e a necessidade de geração de postos de trabalho.

Essas necessidades correspondiam, em muitos países desenvolvidos, à política de welfare, porém são também encontradas em países menos avançados, que buscavam o desenvolvimento econômico no período. No entanto a diminuição do ritmo econômico nas décadas de 60 e 70 nas nações industrializadas e a partir dos anos 80, em países de renda média, bem como a preocupação com os impactos inflacionários dos crescentes gastos público, levou a uma procura de cortes em alguns serviços públicos e a maior eficiência no fornecimento de outros. Tais pressões e o 
final da "Guerra Fria" justificaram uma restrição desses gastos públicos que tiveram a consequiência de uma progressiva reorganização da provisão do setor. Além disso, uma parte da provisão também se deslocou em certas áreas do setor público para o privado ou para organizações voluntárias sem fins lucrativos. ou seja, as mais recentemente conhecidas como Organizações Não-Governamentais (ONGs). Todavia, os serviços públicos permanecem um setor grande e diversificado em muitas economias locais.

\subsection{8 - Questões controvertidas sobre "terceirização"}

Como etapa final de nosso ensaio. colocamos alguns aspectos controvertidos sobre o instituto da "terceirização".

- Da terceirização na área de saúde

Iniciado o atual Governo do Estado do Rio de Janeiro, em 1999, instaurou-se uma polêmica, quando o Governador anunciou o "fim da terceirização na área de saúde".

Considerado um ponto polêmico - pode o serviço de hospitais ser terceirizado? — os Tribunais de Controle manifestam posições contraditórias.

A motivação básica do antigo Governo Marcelo Alencar foi a de que a melhoria imediata dos serviços de pessoal médico no atendimento dos hospitais não seria atingida a médio prazo e o custo de investimento seria muito elevado.

A posição do atual Governo, que retoma a atividade na área de saúde provocou um impacto e instaurou uma grave crise. Procurando superar as diferenças salariais o Secretário de Saúde prometeu conceder uma gratificação para os profissionais de saúde a fim de que haja uma equivalência com os salários pagos pelas cooperativas.

Pesquisas divulgadas em novembro de 1998, realizadas pelo IBOPE indicaram que $60 \%$ dos entrevistados era a favor da terceirização e que os serviços melhoraram, indicando que passaram a ser satisfatórios quanto à qualidade do tratamento recebido.

Os problemas existentes como o da desmotivação e o da ineficiente estrutura existente em cada hospital público foram enfrentados pelo novo modelo.

- De outras áreas submetidas ao processo de terceirização

Além de empresas na área de saúde, outras que realizavam serviços de limpeza em prédios estaduais, como teatros, museus, centros culturais, serviços de vigilância e de segurança também sofreram as conseqüências dessa nova política do Governo Estadual, buscando um corte de $68 \%$ da folha de custeio.

Segundo os dados divulgados pelo Governo do Estado, a redução de gastos com custeio, hoje em R\$150 milhões, também passará por cortes. Segundo esses dados, 15 mil pessoas teriam ingressado no governo através de cooperativas. A folha de custeio atingia, em início de 1999, 25 mil pessoas que prestam serviços para o Estado ou são funcionários de empresas contratadas.

A primeira consequiência imediata dessa decisão de romper os contratos de terceirização de hospitais foi o reconhecimento de que a melhor solução para o 
problema parece ser a transferência dessas unidades para a rede municipal de saúde, numa inquestionável demonstração da impossibilidade de o Estado desempenhar sua função gerencial.

- Da terceirização de serviços na esfera da administração municipal

Os serviços da Administração Municipal assumem uma característica toda especial, decorrente das dificuldades para manutenção de pessoal especializado, capaz de atender a tantos e tão diversificados setores da administração modernizada.

Mais do que no nível da administração federal ou estadual, o Município sofre com a desqualificação do pessoal, com a desmotivação e as limitações salariais.

Um dos problemas a ser enfrentado é o da previdência, o da manutenção do pessoal inativo e as dificuldades para realização de um plano de governo, diante do comprometido orçamento.

Nesse contexto municipal, a utilização do instituto da terceirização parece ganhar outra dimensão, principalmente para resolver três problemas: lixo, saúde e informatização dos serviços.

É certo que a cidade moderna tem no "lixo" um de seus mais angustiantes desafios. Fonte de doenças, de desconforto e de imagens agressivas ao moderno conceito de urbanismo, o Município normalmente não tem como investir na tecnologia e manutenção de veículos e de aparelhos de suporte para a colheita do lixo.

A questão da saúde também merece um exame detalhado. Até que ponto a contratação de serviços terceirizados não pode ferir o controle de qualidade necessário em área tão relevante?

Aqui ressaltamos que alguns municípios têm buscado manter os padrões elevados de atendimento, a partir de um esforço para que os serviços terceirizados não representem uma descaracterização dos programas de saúde. De qualquer forma, a especificidade desse procedimento de terceirização coloca a administração municipal em permanente desafio.

Quanto ao procedimento de terceirização de serviços de informática, duas são as considerações básicas: se é certo que a moderna administração não pode prescindir da tecnologia de uma era de comunicação aperfeiçoada, também é certo que o núcleo dessas informações não pode deixar de ser controlado pela administração, sob o risco de perda absoluta e grave de elementos essenciais à própria segurança da administração.

Mais impotente, por falta de pessoal especializado e de recursos, numa época de constantes crises, a administração municipal se torna mais vunerável a tais necessidades, restando a cada administrador a aplicação do senso crítico para que a solução imediata de hoje não se torne na absoluta despersonalização da administração pública.

\section{3 - Conclusão}

Vimos que, coerentemente com as tendências dominantes de nossa época, no sentido de globalização da economia, do desenvolvimento das parcerias e da institucionalização das diversas formas de participação da sociedade civil e dos cidadãos 
na gestão da coisa pública. ressurgiu em nosso ordenamento jurídico-positivo, após um longo período de relativo esquecimento, a concessão de serviços públicos, a privatização e a terceirização.

Apesar dos inúmeros defeitos que os estudiosos lhe apontam, a Reforma Administrativa vem dar importante contribuição para a estruturação do antigo instituto da terceirização de serviços públicos em novas bases, consentâneas com as exigências da realidade política, econômica e social do momento histórico que atravessamos e, bem assim, com os ditames da constituição da República de 1988, que deu singular relevo aos superiores princípios do serviço público.

$\mathrm{O}$ ressurgimento do instituto, como instrumento de apoio para o administrador público em nosso ordenamento jurídico-constitucional, veio encontrar uma grande receptividade nacional, não somente entre as Administrações carentes de recursos técnicos, de pessoal e financeiros para a realização de obras e serviços reclamados pelo interesse público sob o regime comum dos contratos administrativos em geral, como, também, entre o próprio empresariado, cada vez mais atraído pela possibilidade do retorno do seu capital através da cobrança direta e imediata ao público usuário, e pelo incentivo propiciado por maiores garantias de produção e investimentos mais arrojados e inesperados no cenário jurídico brasileiro.

Assim é que vem surgindo algumas novas espécies contratuais híbridas, que apontam para um uso exagerado do instituto, o que para alguns descaracteriza o funcionamento da administração pública e favorece interesses particulares que apontam para outras relevantes questōes.

Essas espécies contratuais, híbridas entretanto, destinam-se à realização de atividades auxiliares, muito próximas dos serviços públicos, que propiciam a melhor e mais eficiente realização destes. Requerem, por sua natureza especial, grande massa de investimentos financeiros e a obtenção, inclusive, até, em outros países, da transferência de tecnologia altamente sofisticada.

Pela conjugação de todos esses fatores, explica-se, aconselha-se e recomenda-se a aplicação do instituto, desde que tenha por objeto atividades auxiliares da gestão de serviços públicos.

Mas é preciso que os estudiosos do direito administrativo se debrucem sobre a espécie, para melhor examiná-la e dela extrair as necessárias conclusões, ante uma simples indagação: por que isto se torna necessário? por que está acontecendo a multiplicação dos serviços terceirizados?

Será que a noção do contrato administrativo, tal como se acha estruturada em nosso direito positivo, se encontra em crise? Será que as disposições extremamente salutares da Lei $n^{\circ} 8.666 / 93$, no que tange à definição do regime jurídico especial do contrato administrativo, não estão sendo suficientes para proteger adequadamente os interesses da coletividade, encarnados pelas Administrações, e para atrair os investimentos de novos contratados?

A principal questão que se coloca nessa onda de terceirização de serviços é a de que o Estado não pode se tornar refém de interesses particulares, onde o preço cobrado pelos serviços pode ser a liberdade presente e a dignidade futura de várias gerações 
Serviços públicos são. quase sempre. correlatos aos direitos sociais, frutos de tantas e tão laboriosas lutas. De nada adiantará manterem-se em textos normativos. mesmo que constitucionais. direitos arrolados, se do Estado se retirar a obrigação de prestar os serviços sem os quais eles não se tornam efetivos.

Além do compromisso com a eficiência e com a redução dos custos. cabe ao Administrador optar pela terceirização, sem que seja descaracterizada a função do Estado. O instituto da terceirização, visto sob esses novos tempos abertos pela Reforma Administrativa ampliou a sua possibilidade de aplicação, enquanto fez crescer o desafio dos tempos modernos em que a crise da administração pública é a própria crise de sua essência.

\section{4 - Bibliografia}

1 - BRESSER PEREIRA, Luis Carlos. Reforma do Estado para a cidadania: a reforma gerencial brasileira na perspectiva internacional. São Paulo, Ed. 34; Brasília, Enap, 1998.

2 - CADERNOS MARE № 6 - Ministério da Administração Federal e Reforma do Estado.

3 - CADERNOS MARE № 12 - Ministério da Administração Federal e Reforma do Estado.

4 - FERNANDES, Jorge Ulisses Jacoby. A terceirização no serviço público. Brasília, CEBRAD, 1999.

5 - MARTINS, Sérgio Pinto. A terceirização e o direito do trabalho. São Paulo, Malheiros, 1995.

6-MEIRELLES, Hely Lopes. Direito administrativo brasileiro. São Paulo, Revista dos Tribunais, 1990.

7 - MORAES, Alexandre de. Reforma administrativa. São Paulo, Atlas, 1999.

8 -- OLIVEIRA PEREIRA, Cláudia Fernanda de. Reforma administrativa: o Estado, o Serviço Público e o Servidor. Brasília, Brasília Jurídica, 1998. 